\title{
Garfinkel's Politics: Collaborating with Parsons to Document Taken-for-Granted Practices for Assembling Cultural Objects and their Grounding in Implicit Social Contract
}

\author{
Anne W. Rawls ${ }^{1,2} \cdot$ Jason Turowetz ${ }^{2}$ (D) \\ Accepted: 8 March 2021 / Published online: 15 May 2021 \\ (C) The Author(s) 2021
}

\begin{abstract}
From his 1940-1942 studies of Race, through his 1967 study of an "inter-sexed" person called Agnes, Garfinkel's research was always politically engaged. When Garfinkel was Parsons' PhD student at Harvard (1946-1952) and later during a period of collaboration with Parsons (1958-1964), both theorized culture as a domain of social interaction independent from social structure and resting on its own implicit social contract. This conception of culture grounded their respective "voluntaristic" and "reciprocity" based approaches to specifying assembly processes for making social categories in a way that put the empirical assembly of categories under a microscope and made social justice a scientific concern. Garfinkel emphasized the importance of social contract aspects of Parsons' theory - adapted from Durkheim - and with his studies in ethnomethodology, planned to contribute an empirical foundation for aspects of Parsons' position that were criticized for their abstraction. Nevertheless, important differences remained. Parsons' model required assimilation and consensus, thus inadvertently enforcing existing inequalities. Garfinkel, by contrast, was deeply concerned with "structural problems" like inequality, and treated assimilationist positions as scientifically and ethically unsound. His research documented reciprocity as a prerequisite for successful interaction, while treating "troubles" generated by inequality as an important key to understanding social order writ large.
\end{abstract}

Keywords Ethnomethodology · Garfinkel · Parsons · Race · Genderpolitics · Social justice Culture

Jason Turowetz

jason.turowetz@gmail.com

1 Bentley University, Boston, MA, USA

2 University of Siegen, North Rhine-Westphalia, Siegen, Germany 


\section{Introduction}

Although Harold Garfinkel was one of Talcott Parsons' most important and influential students, we know little about their relationship, and associations between their positions are rarely noted. There are many reasons for this, including a mistaken identification of Parsons with French versions of Structuralism, and an equally mistaken labeling of Garfinkel as a Phenomenologist. Garfinkel's criticisms of mainstream sociology (which sometimes included Parsons), and his minority status as a Jew (especially in the 1940's and 1950's), ${ }^{1}$ also led many to assign him an outsider status opposing Parsons that his academic relationships and appointments (at Harvard, Princeton, and UCLA) did not warrant. That Parsons incorporated an interactional position with significant affinities to Garfinkel, and that both focused on culture in interactional terms, has been generally overlooked. ${ }^{2}$ That both focused on issues of politics and social justice broadly conceived (as a concern with the relevance of equality/justice to social order, the ability to act voluntarily, the grounding of social action on implicit social contract and the need for reciprocity and cooperation), has also often been overlooked. This paper sketches the relationship between the two scholars and the critical differences between them, insofar as that relationship and those differences have a bearing on the political (and/or social justice) ${ }^{3}$ significance of their work.

Contrary to the widespread belief that Garfinkel was apolitical and unconcerned with "structural problems" like inequality (cf. Coser, 1975; Coleman, 1968; Eglin, 2017), his work was always politically engaged: from his early focus on Race in the 1940's, to subsequent research on Mentally Ill, Red (Communist), Transgender, SightImpaired, and other marginalized categories (Rawls et al., 2020; Turowetz \& Rawls, 2020; Rawls \& Duck, 2020). ${ }^{4}$ Those who expect research with a social justice focus to take a conventional form will have missed his politics.

Garfinkel focused on the "troubles" that occur when those in marginalized categories participate with majority others in interactional processes that have embedded inequality, and called approaches that overlooked those processes "ethnocentric". In common with W.E.B. Du Bois and others in marginalized categories, Garfinkel - a

\footnotetext{
${ }^{1}$ Jews were not considered White in the US until after WWII (Brodkin 1998). When Garfinkel and his wife, Arlene, traveled through the south, where they lived from 1939 through June 1946, they were treated as "colored" and not accommodated at "White only" establishments. The North didn't have legal segregation, but socially did not treat Jews as members of White middle-class society before WWII.

2 The first chapter of a 1961 manuscript by Garfinkel, titled Essays in Ethnomethodology (an early version of his 1967 Studies in Ethnomethodology), was titled "The Discovery of Culture", and intended as an introduction to the studies in ethnomethodology that Garfinkel and his colleagues were doing at that time - with an explanation of their relationship to Parsons.

${ }^{3}$ By "social justice", we do not intend to call out any particular philosophical approach - or intend any particular meaning of justice. Insofar as Parsons and Garfinkel address issues of equality, fairness, reciprocity and/or the functional consequences of various inequalities, we refer to that as a social justice concern. Similarly, discussions of Race, Gender, Disability and other inequalities are treated as social justice concerns. The argument that inequality is functionally problematic is treated as a social justice argument.

${ }^{4}$ We capitalize terms for social facts and social identities like "Race," "Self," "Other," "Male" "White" and "Black" to emphasize their status as achieved social objects that only exist as they are achieved by participants in interaction. In addition, Race terms were different in 1940 when Garfinkel did his first research. Our discussion will therefore use a mix of historical and current terms where appropriate. We also alternate Black and African-American as both have important but quite different histories in the Civil Rights movement.
} 
Jewish minority - saw the inequality and ethnocentrism embedded in conventional approaches and rejected them. In particular, Garfinkel criticized approaches that treat social categories - like Race and Gender - as if they represented objective facts, without examining how those categories are created (e.g., treating Race and Gender as biologically determined, rather than socially defined categories, or treating a high Black crime rate as if it represented actual crime, rather than recognizing that rate as the direct result of heightened police action and surveillance of Black people).

Garfinkel's argument that the reciprocity and cooperation he called "Trust Conditions"5 are a pre-requisite for successful interaction, informed by Parsons' conception of social contract, built on the idea that inequality produces "trouble" that can be empirically examined to reveal taken-for-granted aspects of social fact making processes. In his $1948 \mathrm{PhD}$ research, Garfinkel proposed that inequality can make "trouble" that leads to nonsense, and in an argument inspired by Sartre ([1945]1995), proposed that in conjunction with attempts to assimilate, "identity anxiety" (among those in marginal categories) can lead to a form of reasoning that rejects facts and accommodates contradiction 6 .

For Garfinkel the study of such troubles is important not only for understanding inequality, but as a window into how all social objects are created; a process that tends to go unnoticed when there is no trouble. In making inequality and the interactional troubles that follow from it the key to revealing how "normal" social order works, Garfinkel placed the minority experience of trouble and inequality at the center of sociological theory and research, making ethnomethodology an intrinsically political approach.

As a PhD student of Parsons' at Harvard from 1946 to 1952, and later during a period of collaboration from 1958 to 1964, Garfinkel and Parsons both theorized culture as an independent level of social structure. Locating "culture" in an action domain that is independent from social structure made it possible, in principle, for the assembly processes for making categories to avoid inequality. It also grounded social fact making processes in an implicit social contract, in a way that put the assembly of social categories under a microscope, while making social justice a scientific concern. The challenge was to document why and how commitment to social contract and equality were necessary in actual practice. Garfinkel contributed an empirical and interactional foundation for this agenda, writing Parsons in 1959 that he was using his studies in ethnomethodology to empirically ground aspects of Parsons' theory that were being criticized because they relied on abstraction (Garfinkel, [1962]2019). ${ }^{7}$

\footnotetext{
${ }^{5}$ Garfinkel uses the term "Trust" in a distinctive way. Unlike Parsons and most others for whom trust is an attitude or belief, Garfinkel's Trust Conditions are a set of prerequisites for situated action. To indicate the difference between these meanings we capitalize the term Trust when used in Garfinkel's sense and use lowercase for ordinary use by Parsons and others.

${ }^{6}$ Later called "cognitive dissonance" (Festinger, 1957), Garfinkel's argument is sociological, and goes a long way toward explaining the conspiracy theory crisis that characterized Donald Trump's Presidency. Excluded people tend to be aware of troubles related to inequality, while majority people with identity anxiety are not: an awareness Du Bois called "Double-Consciousness". Attempts to assimilate confuse the issue. Explanations of the resurgence of racism/xenophobia that ignore such insights often place the blame on an alleged "economic anxiety" among White Americans. Such explanations overlook a prevalent "identity anxiety" deeply rooted in centuries of Race and identity inequality - White privilege - that White Americans benefit from and fear losing.

${ }^{7}$ This paper and others we have published are based on resources in the Garfinkel Archive. All mentions of unpublished documents by Garfinkel and his peers refer to materials in this archive and can be found there.
} 
For both Parsons and Garfinkel (building on an argument made by Durkheim([1893]1933), the independence of culture from social structure had the potential to free social fact making from tradition, making possible a scientific approach to social justice. But, for this conception of culture to actually require justice as a prerequisite (as Durkheim and Garfinkel both argued), the practices in question must be independent from structure in actual interaction; which meant that a form of situated practice that cannot be understood in terms of broad cultural and symbolic traditions must be clearly distinguished.

Because Parsons' theory required limiting variation and contingency, and he relied on standardization and unified values to get that done, he had a problem meeting this requirement. His theory enforced a single cultural system to the exclusion of others even his situated practices (Pattern Variables) oriented unified values - with stratification operating as a reward system for conformity (among other functions). Thus, Parsons' approach to culture was sometimes based on interaction, while at others it relied on symbolic systems and broader structures. This led to confusion, which Robert Bellah and Clifford Geertz attempted to resolve in favor of symbolic systems. Most scholars have followed Bellah and Geertz in their interpretation of Parsons (Rawls \& Turowetz, 2019).

By contrast, Garfinkel emphasized Parsons' interactionism, and in his own work avoided the confusions that beset Parsons' approach by treating contingency and variation (of rule, sequence, and placement) not as problems, but rather as information that can be a resource for making certainty from contingency in local orders of practice. Garfinkel's research documented the "ethno-methods" and Trust Conditions that support this interactional process. Because conformity is not necessary for Garfinkel, stratification is not needed to reward conformity.

Deviance and/or lack of consensus on broad social values are not problems for an independent interaction order. What is required is commitment by all participants to situated interactional expectations and prerequisites. Garfinkel's research aimed to demonstrate empirically that, to the extent local practices embed inequalities that interfere with these prerequisites, trouble will occur, meaning cannot be achieved, and interaction will enforce the status quo by default.

In this article, we first consider the relationship between Parsons and Garfinkel. Second, we discuss Garfinkel's approach to social justice and its connection to Parsons. Third, we describe Garfinkel's early research on Race and other marginal categories (Garfinkel, 1940, , 1942/1949, and 1947). Fourth, we analyze his $1948 \mathrm{PhD}$ research on the "troubles" experienced by people in minority categories who have "identity anxiety" and how they respond when their pre-suppositions are challenged. Fifth, we trace the development of the "Trust" argument from 1948 to 1967. Sixth, we discuss the collaboration between Garfinkel and Parsons from 1958 to 1964 (the basis for Parsons' Primer). Seventh, we consider differences between Parsons and Garfinkel on stratification and value uniformity. Eighth, we examine differences in their understandings of Trust/trust. Ninth, we discuss the overall importance of Parsons to Garfinkel's approach. Finally, we conclude with a discussion of the political implications of Garfinkel's ethnomethodological approach.

The Relationship between Parsons and Garfinkel While both had challenged the discipline in similar ways before they met in the 1940's, Parsons and Garfinkel did not come into direct contact until Garfinkel arrived at Harvard in 1946 and Parsons became his mentor. While there likely was mutual influence during the early years, and 
there are references to comments and feedback from Parsons on Garfinkel's work in the context of courses in 1946-7, their active collaboration did not begin until 1958, after Garfinkel went to UCLA, and lasted until 1964. Initiated by an invitation from Parsons in September 1958 to attend a small conference at Harvard on Parsons' recent work, ${ }^{8}$ Garfinkel began articulating how his own approach to culture as an independent level of interaction and practice could empirically anchor aspects of Parsons' more abstract approach. Garfinkel explained this in a series of letters to Parsons and others in August 1958, and eventually in a manuscript titled Parsons' Primer (Garfinkel [1962]2019, in which some of these letters are reproduced).

For both scholars this collaboration picked up threads of a shared pre-war concern about a growing split between qualitative and quantitative approaches in sociology. In the 1930's Parsons (1938) had attributed this split to a confusion in social theory, driven by an emphasis on individualism (inherited from Comte) that undercut the discipline's social fact foundations. He criticized American sociology for overlooking newer European approaches to social fact making.

In so doing, Parsons was joining Park (1926) and others who were insisting on the importance of social facts in the face of a growing quantitative positivism. Unlike the others, however, Parsons maintained that the prevalent approach (even by Park) was part of the problem. In treating social facts as durable aggregations of individual action over time, even Park and other "interactionists" were reifying culture and encouraging a positivist counting of categories. The solution Parsons proposed was to follow the insights of Durkheim and Weber in treating social facts as fragile objects that must be achieved in the moment independent of social structure. He warned that not doing so was creating an artificial division between qualitative and quantitative approaches.

In his 1942 MA Thesis on the effect of racialized accounts on homicide cases, Garfinkel made a similar point about the importance of social categories and the pitfalls of ignoring their social construction and use. In spite of these warnings, however, the tendency toward the positivist reification of categories increased during WWII, as sociological elites turned in a more exclusively quantitative direction (Rawls, 2018). Garfinkel ([1962]2019: appendix) described the result as a conflicting "interest" in and "fear" of, sociological theory.

The 1940's had found Parsons and Garfinkel both opposing the development in sociology of what we now know as the micro/macro and qualitative/quantitative dichotomies: treating those distinctions as artifacts of a failure in U.S. sociology to incorporate a practice based approach to social facts and social contract. In a wartime context that abandoned social justice issues as unscientific, both also stood apart from their peers in building on Durkheim's argument that justice is a pre-requisite for social fact making in diverse and differentiated modern social contexts. ${ }^{9}$

\footnotetext{
${ }^{8}$ It is not clear from the letters, or the manuscripts Garfinkel lists for his courses what this manuscript was.

${ }^{9}$ While Parsons thought justice could be accomplished within a unified cultural framework, Garfinkel disagreed, taking a more nuanced approach. Whereas Parsons had grounded his argument primarily on Durkheim and Weber, Garfinkel (who had read and incorporated Parsons' reading of their work in 1939) was also influenced by the interactionism of Thomas and Znaniecki, Gurwitsch's theory of embodied action, and Burke's theory of accounts; all of which he had studied at North Carolina. During Garfinkel's first year at Harvard, a graduate position on a research project with Jerome Bruner (the famous "narrative" psychologist), added another dimension (involving how people respond when evidence contradicts their beliefs) to his empirical approach to the assembly of culture (and information) as independent from social structure. He soon after encountered the work of Schutz.
} 
Articulating an independent interactional status for culture was the central pillar of both positions, grounding not only their approaches to social facts, but also their conceptions of social contract, and the relevance of their positions to social justice. Conceiving an independent level of culture grounded Parsons' theory of "voluntaristic action", which is essential to his conception of politics. Ideally, members of Parsons' society voluntarily orient a set of shared values and practices for creating social objects, which they have been socialized to accept. Deviance for Parsons (1951) was the result of failed or incomplete socialization.

For Garfinkel, the social justice relevance is twofold. First, achieving independent and fragile cultural objects requires close cooperation and implicit commitment to local practices and their Trust Conditions rather than adherence to a single set of broad values. Local situated practices also require a commitment to equality/reciprocity that is different from commitment to general values. Second, Garfinkel had a methodological concern. The processes involved are "taken-for-granted" - not available to consciousness (unless trouble arises) - so most majority people (including most sociologists) are not aware of them. He argued that an approach that reveals these taken-for-granted practices - or ethno-methods - by carefully documenting and analyzing trouble, is necessary before researchers can understand how cultural objects (social facts) are being made. ${ }^{10}$ Durkheim had placed a similar emphasis on new methods.

Garfinkel's first publications (1940, 1942, 1949) examined how accounts, categories, and social facts (often represented as statistics) can embed Race inequality, focusing on a segregated bus in Virginia (Garfinkel, 1940), and the use of racialized accounts in North Carolina courts (Garfinkel, 1942; 1949). In later work, he continued to focus on troubled interactions, to reveal hidden aspects of social practices, both naturally occurring (e.g. involving persons in socially marginalized identities who have "natural" trouble participating in society: Black, Jewish, Transgender, Blind, etc.), and interactional trouble induced by the researcher that participants cannot make ordinary sense of: exercises that came to be known as "breaching" experiments. Garfinkel's preference was for natural troubles except as "tutorials" for getting students to recognize hidden social processes.

In revealing tacit assumptions, ethnomethodology can produce a heightened awareness -a kind of "double consciousness" (Du Bois, 1903) - making what had been hidden available to conscious reflection. Like the natural experience of double consciousness of racism, described by $\mathrm{Du}$ Bois, or the natural troubles Garfinkel described with regard to Agnes' experience with Gender (Garfinkel, 1967), the awareness induced by studying interactional trouble reveals taken-for-granted assumptions and processes - and the inequalities they rest on and create - that the marginalized are forced to manage, while their

\footnotetext{
${ }^{10}$ The status of the knowledge to be discovered as "embodied experience" is why Garfinkel stressed unique adequacy. It is not always necessary for a person to have the experience for themselves - as is certainly not possible in studies of Race and Gender exclusion. But, it is necessary to get a sense of the knowledge as an experience. This requires very detailed observations and immersion in settings.
} 
majority counterparts typically remain unaware (Duck \& Rawls, 2020). This makes ethnomethodology an inherently politically relevant approach.

Garfinkel/Ethnomethodology and Social Justice Ethnomethodology - a term Garfinkel first used in 1954 while reporting on the famous Chicago Jury study ${ }^{11}$ - developed out of his concern to understand the origins and consequences of social injustice. The son of Jewish immigrants who experienced racism and exclusion, Garfinkel sought to understand how tacitly racist, gendered, classist, ableist, and western-centric categories and assumptions were embedded in the structures of ordinary commonsense practices, why they are inimical to a pluralistic modern society, and what might be done to expose and uproot them.

Along the way Garfinkel also realized that the troubles associated with inequality could reveal how social practices work in general - making the excluded and their experiences the key to a broader understanding of social order (Rawls et al., 2020). From his earliest writings on anti-Black racism and anti-Semitism, Garfinkel (Garfinkel, 1940, 1942, 1947, 1948, 1949) criticized U.S. sociology for uncritically incorporating tacit assumptions involving these categories into its theories and methods, a practice Garfinkel (1946) called ethnocentrism.

Garfinkel was initially drawn to Parsons' (1937) adoption of Durkheim's conception of society as based on implicit social contract, because it treats social justice as intrinsic to social order and meaning (which Garfinkel explained in Parsons' Primer, Chapter 4). Working in the Durkheim/Parsons lineage, Garfinkel also emphasized Durkheim's point that in diverse modern societies social facts need to be constantly made and remade using constitutive practices in local contexts of implicit social contract. Focusing on interaction as the site where social facts are assembled using shared practices - "ethno-methods" - grounded by an implicit social contract he (Garfinkel, 1963) called Trust Conditions, Garfinkel set out to document the argument empirically.

The big problem from Garfinkel's (1946) perspective is that these interactional processes - through which everything is made - were being taken-forgranted, even by Parsons and those like Znaniecki (1936) who called themselves interactionists. Their focus was on individuals and connections between individuals, rather than on the substance and form of the interaction between them. No one was examining how social objects were being assembled by coordinating action during interaction. Consequently, even approaches called interactionist remained individualist and abstract, and the objects created in interaction - from categories to statistics - were being naively treated as if they represented natural facts. Thus, the processes that create categories and statistics, and the way they embed inequality, remained generally unacknowledged, creating a false appearance of "objectivity" for categories and methods for using them that are actually "morally loaded".

\footnotetext{
${ }^{11}$ Also reported in Chapter Four of Studies in Ethnomethodology (1967), the Chicago Jury Study included Saul Mendlovitz and Fred Strodtbeck, who knew Garfinkel and later became friends. By the time Garfinkel was brought on board in 1954, the data had already been collected. Garfinkel helped with the analysis and the first presentation at ASA.
} 
Garfinkel's insistence on detailed ethnographic observations of practices was intended to heighten awareness of the taken-for-granted aspects of social interaction and his articulation of the Trust Conditions that must be satisfied for interaction to succeed were important elaborations on Durkheim and Parsons that aimed to expose this moral loading. Unfortunately, during WWII, sociology became more individualistic and quantitative, abandoning Durkheim's conception of social facts (and Parsons') in favor of a position closer to Comte's "consensus" based argument (Rawls, 2018). This left Garfinkel in a precarious position. He was making an important elaboration on a sociological classic (Durkheim) while working with a prominent scholar at Harvard (Parsons). However, changes in sociological theory and methods had pushed the discipline so far in an individualistic and quantitative direction by the 1950's, that both Parsons and Garfinkel found themselves being marginalized. Garfinkel, in particular, was treated as if he were an outsider whose interests were trivial and unscientific.

Contrary to the belief that Parsons set the agenda for U.S. sociology in the Post-War years and determined its theoretical orientation, the discipline started moving away from Parsons during WWII. While a version of structural-functionalism did enjoy its heyday in the 1950s and early 1960s, and Parsons himself remained influential, the theory he was known for was largely a straw man position, the popular form of which did not reflect Parsons' argument. The Durkheimian foundation of Parsons' theory was misunderstood by most scholars, who based their research on the individualist and positivist premise that societies (and social facts) are aggregations of individual action and dispositions grounded in consensus, and therefore, that social objects are durable and can be quantified and counted like natural objects: a position Durkheim and Parsons rejected. This misinterpretation resulted in an overly "structural" version of Parsons that invit|llled the subsequent criticism by "post-structuralism".

This led to various attempts to explain Parsons, including the attempt by Geertz and Bellah to explain his conception of "culture" (and Kroeber \& Parsons' 1958 response), and Robert Dubin's (1960) attempt to explain the Pattern Variables. Parsons' own increasing turn toward interaction, and his continual revisions to the Pattern Variable argument, resulted in his (Parsons, 1960) Response to Robert Dubin (on which he collaborated with Garfinkel) in which he explained that while he believed that Dubin was trying to be helpful, his interpretation of Parsons' argument was so misconceived and the argument had changed so much that a comprehensive clarification was required. While sociology textbooks continued to reflect the influence of an early (and even then misinterpreted) Parsonian theory even into the 1980's, Parsons himself had long before taken a direction he never did become known for.

While Parsons was able to retain his influence for a time in spite of these misunderstandings, by 1962, his vibrant European social fact approach to sociology was being supplanted by a version of social theory - construed as sets of propositions - that still predominates. Garfinkel (1946), who was even more openly critical of the move toward quantitative methods and positivism, argued that sociology was taking for granted what it needed to explain: how people make sense together and how interactions work. Being more openly critical he was also more quickly and thoroughly ostracized. However, by the time the two began collaborating in 1958, Parsons was finding the level of misunderstanding of his work - even by friends like Dubin - 
intolerable, and was starting to make it clear that he too was moving toward a social interactionism very like Garfinkel's. ${ }^{12}$

In positioning his research in the Parsons/Durkheim social contract lineage, Garfinkel was developing and empirically grounding the argument that equality and reciprocity - his Trust Conditions - are necessary for making self, social objects, and meaning in diverse societies; and that where these conditions are not met, meaning is lost, exclusion is inevitable, and social justice impossible. Far from being apolitical, the Trust argument, which stands at the core of ethnomethodology, grounds an imminent critique of any social system that fails to ensure that all members have equal access to the practices and categories for making sense and self. Many ethnomethodologists and conversation analysists have documented in detail how social practices can produce and maintain racism, inequality and exclusion (Rawls et al., 2020).

\section{Garfinkel's Research on the Racism and Inequality Built into Social} Categories Garfinkel's publications on social justice issues include "Color Trouble," in 1940, his MA thesis on "Inter and Intra-Racial Homicide" in 1942 (a later version of which was published in Social Forces, Garfinkel, 1949), and his paper for the Harvard project on attitudes toward Russia, "The Red as an Ideal Object" (written spring 1947, published 2012), on the role of social categories - including the Red category (communist) - in maintaining social boundaries, hierarchies and exclusion. ${ }^{13}$

When Garfinkel went to North Carolina to attend graduate school in 1939, he had already experienced anti-Semitism, but was shocked by the anti-Black racism he found there. Working with Howard Odum and Guy Johnson, both well-known scholars of Black American culture, Garfinkel began observing and writing about racism. His first publication, "Color Trouble," describing racism on a segregated bus Garfinkel was traveling on in spring 1940, appeared in the Urban League journal Opportunity that May. The article is interesting both for the incident it describes, and for its focus on the way racism worked through accounts and presuppositions in interaction. For his 1942 MA Thesis Garfinkel studied how Race was invoked in courtroom accounts (by judges, prosecutors, defense attorneys and witnesses) in ways that determined case outcomes, but then disappeared in the statistical record, making it look as if Race and racism had nothing to do with the courtroom process, when it had everything to do with it.

\footnotetext{
${ }^{12}$ At that point Parsons was also involved in the dispute with Bellah and Geertz over symbolic meaning that resulted in his short ASR paper in 1958. It is ironic that the Geertz/Bellah adaptation of Parsons' position, which Parsons rejected and which focused on the symbolic dimension of his conception of culture while ignoring its interactional dimension, has since become confused with Parsons' position as such. By ignoring the interaction side of Parsons' two-sided conception of culture, Geertz wound up arguing that culture is a symbol system, that it is autonomous from social structure, and that it stands above and controls social structure in a kind of cybernetic hierarchy (Lizardo 2016: 108-109). As a result, Parsons is criticized for asserting that ideal, non-empirical cultural objects (e.g. ideas) somehow influence empirical processes (see, for example, Lizardo's [2016] critique of Parsons), when in fact this was never Parsons' position. Like Garfinkel, Parsons recognized that all social objects, including ideas, need to be made and grounded in empirical practices, a point Durkheim had argued decades earlier (for an elaboration of this argument, see Rawls \& Turowetz, 2019).

${ }^{13}$ That Garfinkel tried several times to get this article published is attested to by the rejection letters he received that were preserved in his archive. In one of these letters the editor suggests that Garfinkel is not doing sociology but psychology and suggests that he submit the article to psychiatric journals. This explains why several of Garfinkel's subsequent articles were published in psychiatric journals, which at first seems strange - but shows that he took the advice he was given.
} 
After he left North Carolina, Garfinkel continued to do research on persons in marginal identities, whose difficulties satisfying the expectations of majority actors made them what he called "natural experiments." In addition to Black Americans, these natural experiments included: Mentally-ill soldiers Garfinkel observed during the war while working as a psychologist at an Army hospital; Russians and Communists (Garfinkel, 1947), Jewish students (Garfinkel, 1948), and Criminals (Garfinkel, [1947]2012) Garfinkel did research on during his Harvard years; and Transgender and sight- impaired persons he studied at UCLA (1958-1967).

Garfinkel's Jewish identity is an important part of the story. Before and during WWII Jews were not considered White in the US and their participation in elite institutions and professions was limited (see footnote 1). For his $\mathrm{PhD}$, Garfinkel formulated an argument loosely based on an essay by Jean Paul-Sartre ([1945]1995) on anti-Semitism, and gave it the provisional title "The Jew as a Social Object." He was studying what is now called "cognitive dissonance" - the treatment of disconfirming information as if it was confirming - and postulating a relationship between that form of reasoning and the desire to assimilate. ${ }^{14}$ In other words, he argued, those trying to assimilate into a group that is not their own are more likely to treat disconfirming information as if it was what they had believed all along. That his $\mathrm{PhD}$ research addressed this issue was obscured by the Harvard Graduate School's demand that he change the title (the discussion of Jewish assimilation was also removed likely also by request). Nevertheless, the Jewish assimilation dilemma and its effect on reasoning continued to center his $\mathrm{PhD}$ project.

Garfinkel wanted to know whether the contrast drawn by Sartre between four orientations toward Jews (one of which is similar to Franz Fanon's, 1952 “colonial mentality") could be reproduced in controlled experiments with Jewish and White Harvard students. ${ }^{15}$

The key point is that excluded minorities constantly need to take the perspective of strange and unknown Others toward themselves. This is literally impossible and there are many hazards involved in trying to do it. Moreover, it is something the White majority rarely needs to deal with. When majority persons are forced to confront the Other's viewpoint, they can usually dismiss it as uninformed. By contrast, the minority position is always subject to challenge and rejection. Coping strategies to deal with these rejections (including cognitive dissonance and refusing to respond) are used to preserve intact conceptions of Self (Rawls \& Duck, 2017). ${ }^{16}$

The significance of being Jewish followed Garfinkel throughout his career. Many of his principal graduate students were Jewish, and their discussions often touched on

\footnotetext{
${ }^{14}$ Garfinkel was proposing this 10 years before the theory was first proposed by Leon Festinger in $A$ Theory of Cognitive Dissonance (1957).

${ }^{15}$ Whereas Sacks (1992, Vol. I:180) would later talk about categories and category-bound activities that are "protected against induction," in his $1948 \mathrm{PhD}$ thesis research, Garfinkel was proposing a form of reasoning that is protected against induction (i.e., no amount of exceptions will change the original premise).

${ }^{16}$ In Tacit Racism (2020), Rawls and Duck explain why in the US it is so often White Americans who occupy this "assimilation" position. Many European immigrants came from countries that prior to WWII were not considered White (these include Italians, Spanish, Greeks, Polish and Eastern Europeans in addition to Jews). The attempt to assimilate has a well documented effect in which the second generation turn away from their heritage. The fact that poor White people have from early colonial times aspired to become like rich Whites has also played a role. In contrast, barriers to assimilation combined with double-consciousness have protected most Black Americans from this dilemma. Thus, while Sartre and Garfinkel are describing the problem in terms of assimilation - it tends to be more of a problem for White Americans and those groups like Hispanics who calibrate Whiteness differently, than it is for Black Americans.
} 
racism and exclusion. ${ }^{17}$ With Egon Bittner, who became his student in 1955, Garfinkel analyzed the order properties of German concentration camps, of which Bittner had personal experience as an inmate at Auschwitz. Garfinkel's archive contains four volumes of transcriptions of survivor narratives made in 1946 and 1947. What Garfinkel learned about how concentration camp guards varied their practices to make it impossible for camp residents to make sense of events - one time sending the front of the line to the gas chamber, the next time sending the end of the line, and then the middle - informed his formulation of the Trust Conditions for stable meaningful interaction. He was still using concentration camp examples to explain Trust Conditions during his lectures at Boston University in 1975.

"Color Trouble" 1940: Institutionalized Accounts and Tacit Presuppositions In "Color Trouble," Garfinkel analyzed a racial incident he observed on a bus ride from Newark New Jersey, where his family lived, to North Carolina, where he was a graduate student. The bus stopped in Petersburg, Virginia, on May 23, 1940. When the other passengers got off, two Black passengers were left sitting in the middle seats, rather than at the back where the Jim Crow law of the time required them to sit. One was dressed as a woman, the other as a boy. The "boy" was, unbeknownst to Garfinkel, Pauli Murray, a famous transgender civil rights activist. ${ }^{18}$

The driver told the women he could not load new passengers until they moved to the back. They offered to move partway back into a broken seat if he could fix it. The driver initially accepted the compromise as preserving the appearance of Jim Crow, and fixed the seat. The agreement broke down, however, after he had fixed the seat when one of the women asked for an apology. For the next several hours the bus remained in Petersburg while the driver had the women arrested.

When the woman asked him for an apology, Garfinkel (1940:113) described the driver as enraged. Just as it seemed he had worked out a compromise, Murray's companion asked for an apology: (Garfinkel, 1940:113) "You're a gentleman, and I'm a lady....and therefore... I think that as a gentleman to a lady you owe me an apology." In Garfinkel's account, the threat to Jim Crow involved in the request to recognize a Black woman as a "lady" prevented further compromise: "Growling and blind with rage, he was out of the bus in three clattering leaps. '...fool...' He was yelling for the police even before he was out of earshot" (Garfinkel, 1940:113). Angry that his efforts had failed, and enraged at her challenge to the Jim Crow foundations of his world, he has nothing more to say. There are consequences when the compromise collapses: The driver is embarrassed, the passengers are embarrassed. The veneer that normally hides the ugliness of Jim Crow was lifted and the whole social situation collapsed.

The article reporting Garfinkel's observations first appeared in Opportunity within days of the incident. Although the analysis employs literary devices (representing the thoughts of participants) that Garfinkel did not use in later work (and was reprinted twice as if it were fiction in Best Short Stories of 1941 and in Primer for White Folks, 1945), the 22-year-old Garfinkel did not write it as fiction, but as ethnography. The

\footnotetext{
${ }^{17}$ Recordings of some of these and also letters and papers are preserved in the archive.

${ }^{18}$ To complicate matters, Murray was secretly a cross-dressing female - identified by Garfinkel as an adolescent boy. Garfinkel's description of Murray as a "boy" is consistent with his discussion of Agnes (a transgendered person) as a woman. Murray "presented" as a boy - and hoped to be seen as a boy. Garfinkel obliged. Murray's account can be found in the Harvard University Schlesinger archive.
} 
literary devices portray tacit presuppositions about Race and inequality that Garfinkel observed at work in the interaction. These include accounts given by various passengers, and the official accounts the bus company would accept for the bus being late (which included Jim Crow "color trouble"). If the company did not accept such accounts, the driver could still act on his racism, but would have trouble doing so without being fired because of the long delay involved. This focus on accounts was inspired by courses Garfinkel had taken in Accounting as an undergraduate, in combination with graduate studies of Kenneth Burke's $(1939,1945)$ theory of accounts.

Later studies by Garfinkel and his students and colleagues would document how tacit presuppositions and institutional accounts can interfere with reciprocity and Trust conditions, distorting sensemaking and statistical accounts in a wide variety of institutional settings (notably Weider, 1974, Sudnow, 1965, and Meehan, 1986, Meehan \& Ponder, 2002). The institutions that most sociologists treat as the bedrock of democracy - including the police and "the rule of law" - Garfinkel revealed as agents of inequality whose statistical records reflect that inequality.

"Inter and Intra-Racial Homicide" 1942: Racialized Accounts in Court Garfinkel's second major work, his 1942 MA Thesis on Inter- and Intra-Racial Homicide, focused on how courtroom outcomes that appear statistically to be "fair" were actually based on racialized accounts produced in court as part of the trial record (a revised version published in Social Forces 1949 incorporated category arguments from the 1947 manuscript "The Red"). At a time during WWII when sociology was turning toward quantitative methods, Garfinkel was documenting the pitfalls of a statistical approach, particularly in measuring racial discrimination. The assumption that research based on statistics is "objective" is false when the numbers refer to trial verdicts and sentences produced using institutional accounting processes that treat Race and racialized narrative accounts as an intrinsic, but taken-for-granted, aspect of the legal decision- making process. The same is true of policing and crime statistics today.

Garfinkel focused on accounts tied to Race categories offered in ten county courts by those involved officially in the cases (attorneys, prosecutors, judges and witnesses). While these racialized accounts played a key role in determining case outcomes, when looked at statistically the distribution of punishments by Race looked "fair." Garfinkel was able to demonstrate that the results of two contrasting sets of accounts neutralized each other such that statistically it looked as if Race were not playing a role in the determination of cases when Race was actually playing the determining role.

Prosecutors, judges, lawyers and witnesses produced accounts for the trial about the moral character of both the offender and the victim: character assessments. These accounts were framed in terms of shared cultural assumptions about Race. Black and White men are not expected to behave the same way, and these "category-bound" expectations frame judgments of character made in court (e.g. "good" White men "contribute to the community", "good" Black men "know their place"). Garfinkel found that when the victim was Black, "good" White men were rewarded (with lenient sentences or dismissal) for killing "bad" Black men. "Good" Black men were also rewarded for killing "bad" Black men and "doing the community a favor." Statistically (holding constant other factors), White and Black men in these two categories had a similar probability of lenient sentences.

The more lenient sentences for White men killing any Black man and Black men killing bad Black men, cancelled each other out and obscured the racial bias in sentencing. When 
the victims were White, both Black and White men received harsher sentences, although Black men were much more heavily penalized. Not only was the fact that Black men were always penalized for killing White men, while White men were rewarded for killing Black men obscured, but the fact that trial outcomes were based on racist courtroom accounts that reinforced the systemically racist framing of Black men was hidden. Furthermore, the harsh sentences that occurred when Black men killed White men made up such a small percentage of cases (because most homicide occurs within Race and most victims are Black) that they did not effect the overall average.

The numbers were lying. A situation that in the courtroom was openly discussed in racialized terms appeared statistically to be the result of a just and fair legal process without racial bias. It is a huge problem that actions explicitly determined by Race and tacit assumptions about Race can look fair in the aggregate. It is also remarkable that given Garfinkel's $(1942 ; 1949)$ demonstration of how racism can be rendered invisible by statistics, US courts today require claims of racial (and other forms of) discrimination to be accompanied by statistical proof that an institution has a "pattern" of bias. ${ }^{19}$ Given the moral loading built into the numbers, this is usually impossible.

"The Red" 1947: The Categories "Red" "Jew" "Negro" and Criminal "The Red as an Ideal Object," added several dimensions to Garfinkel's earlier approach. Completed in the spring of 1947 (Garfinkel, [1947]2012), while Garfinkel was working with both Jerome Bruner and Parsons on a study of American attitudes toward Russia, the paper elaborates on a theory of social objects he was developing his first year at Harvard that pulled together his earlier observations about tacit presuppositions and hidden features of Race categories. "The Red" also reflects the insight he gained from working on the Russia project that some people will stick with their pre-conceptions, even when the evidence contradicts them (cognitive dissonance), along with exposure to the research practice of creating trouble to expose the underlying beliefs and practices of research subjects (see Smith et al., 1956). ${ }^{20}$

The "Red" in the title refers to the American attitude toward Russia after World War II, when anti-communist sentiment was high. In writing about the functions of the "Red symbol," Garfinkel contrasts the moral loading of the symbol and how it works, with the way the symbols "Negro" and "Jew" and "Criminal" work. ${ }^{21} \mathrm{He}$ analyzes these categories in terms of symbolic pairs: good/evil, sacred/secular, benign/malignant, and insider/outsider, arguing that they invoke moral meanings that attach to and define people without their consent. $^{22}$

\footnotetext{
${ }^{19}$ Because they are accountable in various ways, most institutions have become adept at making sure that their institutional accounting practices leave no such "pattern" of bias.

${ }^{20}$ Bruner explained to me (Rawls) that some of this technique was inspired by his work with the OSS after WWII. When they went into French villages they found that people who had been living under German occupation had an amazing ability to cling to false realities that they had built for themselves. It could be very hard to produce any cracks in that reality.

${ }^{21}$ In private conversation Garfinkel has talked about how members of his family were on both sides of the law in the ethnic enclave in which he was raised. Stories were told about relatives hiding out in their house.

22 That they don't consent is a key point here. With regard to his Bastrop notes (Garfinkel, 1952a: appendix) Garfinkel related a story about a man he tried to talk to during his fieldwork in Texas. The man had a problem with Garfinkel being Jewish. Garfinkel tried to move the discussion to a higher level of abstraction - saying that they both believed in God. But, the man wasn't having it. He kept saying "but you are Jewish". It was a category assigned without Garfinkel's consent that interfered with his fieldwork.
} 
Although "The Red" was written during his first year at Harvard, it addresses many of the questions Garfinkel would develop later. The entire meaning of an object, what it is "as an object of action, is found," he says (Garfinkel, [1947]2019:19) "in the meanings it has for an actor employing a given way of attending to these meanings." That there is more than one kind of social object, and that the processes of their constitution and how they "mean" are different, is a central point. This multiplication of object types challenged the sociological wisdom of the day, which was increasingly tending toward a unified conceptual approach. Garfinkel was finding order and meaning in the multiplication of object forms and contingencies while the rest of sociology (including Parsons) was trying to reduce contingencies.

According to Garfinkel ([1947]2012:19), "The Red is an ideal object in the same way that we say a triangle is an ideal object." The point is that "The term Red refers to an object which does not exist; rather it is meant." Some objects have existence in their own right - even though as meant they are social objects. Other objects exist only as "meant" and have no other existence. John Searle's (Garfinkel, 1967) Speech Acts are social objects of this second type. As Garfinkel points out, triangles and social categories like "Red" "Negro" and "Criminal" only exist as meant social objects and have no other mode of existence. This means that as an object the "Red" depends entirely on "the 'manipulations' of various systematically related ideas and beliefs." Garfinkel gives the example of a "triangle" as such a meant (or ideal) object. The same is true of "Negro" as an ideal object: it has no "real" or biological counterpart. ${ }^{23}$

There are "constitutive prerequisites" for various states of such ideal objects. These include interactional practices and a working agreement with regard to them that specify: 1) The identity or identities from which (or by which) a particular object can be constituted; 2) The situation in which it can be constituted; 3) The other identified objects against which it can be constituted (e.g. Black/Criminal), and so on. According to Garfinkel ([1947]2012:27), such objects also have roles. These role properties belong to situations/interactions and are constitutive of the objects that are said to take on those roles. To say that an object has role properties (or that in a situation an object has a certain role), is to say that it is bound by the obligations of that role. For Garfinkel the "Red" as a social object carries certain moral tones of obligation and role relations as a constitutive property. That "Negro" carries moral properties in much the same way he had demonstrated in his MA Thesis. The moral loading is part of the social category.

This was not how conventional sociology analyzed categories. George Lundberg (1944) had famously argued in 1943, as president of the American Sociological Association, that scientific clarity could only be achieved by getting morality and emotion out of science, and he made the argument with direct reference to the work of Jewish sociologists - who he accused of having an interest in social justice. While Lundberg's position was extreme, it was echoed by many other sociological elites during and after WWII (Rawls, 2018). There was a general sense that justice was not a scientific concern. According to Garfinkel ([1947]2012:21), moral issues were typically felt to "complicate the objective clarity of a symbol's meaning." But, he argued, this was a mistake because in actual use the "Red" symbol, like other ideal symbols, gets its objectivity from "the maximum heaping up of these emotional factors." For some

\footnotetext{
$\overline{23}$ These are categories that Sacks (1992) would say are "protected against induction" because facts cannot change the ideals and accounting practices that are bound to the categories.
} 
important social objects like "Red" and "Negro", Garfinkel argued, emotion and morality are constitutive of the objective clarity of the object. These symbols do powerful work in the social world by tapping into morality. To remove their moral character is unscientific and would in all such cases lose the "objectivity" of the object.

According to Garfinkel ([1947]2012:25), "There is a requiredness about the meaning evoked by these symbols." 24 The test of the "truth" of the use of a term is in the reaction of people in ordinary interaction - not in scientific logic, or the thought experiments of scientists - but in the practical logics of combination attached to them. Following through on this advice would require recording actual conversations, which Garfinkel began doing for his $\mathrm{PhD}$ research in 1948.

The Insight that "Trouble" Reveals What Has Been Taken-for-Granted Having focused (in Garfinkel, 1940, 1942/1949, and [1947]2012) on interactional processes embedding racism against Black Americans, and in 1947 on categories and practices related to attitudes toward Russia and communism, Garfinkel turned in 1948, in his preliminary $\mathrm{PhD}$ research to problems faced by Jewish Americans, like himself. He was interested in particular, in whether trying to assimilate and "pass" as White (e.g., joining the majority group as a doctor) would effect the way Jewish students handled incongruous information that challenged their normative preconceptions. Inspired by the project on attitudes toward Russia - for which he had administered a "stress test" that challenged participants' evaluations - Garfinkel developed a similar research strategy for his dissertation that involved getting premedical students to evaluate a recording of an interview with a pre-medical candidate, and then telling them their evaluation was wrong. The objective was to find out how those with high identity anxiety (whom he expected to be Jewish) would respond when their evaluations were challenged: Which students would admit they had been wrong when presented with disconfirming information, and which students would come up with rationalizations that claimed the disconfirming information actually accorded with their preconceptions?

Garfinkel expected students in marginal Jewish identities with high identity anxiety, who were hoping to assimilate by becoming doctors, to adhere more tightly to their preconceptions when challenged. He expected them to find ways to rationalize the disconfirming information as supporting those preconceptions, even when that involved contradiction. By contrast, he expected students with low identity anxiety to reevaluate their preconceptions when presented with contradictory information. ${ }^{25}$ The tools Garfinkel developed for documenting how inequality interacts with incongruity were intended to add empirical detail to Sartre's ([1945]1995) analysis of the intersection

\footnotetext{
24 This "requiredness" protects the symbols against the contingencies of interaction: people who are committed to the symbol and the meaning it carries will find ways to interpret incongruous information that may arise in any given situation as confirming what they already believed - even if it means holding contradictory ideas simultaneously. Garfinkel would observe this same sense of "requiredness" in the way premedical students treated incongruous information about the category "doctor" and Agnes treated incongruous information about the male/female binary, to which she herself tried to conform despite being transgendered.

${ }^{25}$ We argue that Garfinkel was articulating an early version of what Franz Fanon (1952) later identified as the "colonial mentality". That is, that oppressed minorities, in attempting to assimilate into the majority, become strict adherents to the majority view even when it explicitly discriminates against persons like themselves. It is also like cognitive dissonance - insofar as those attempts to parrot the majority view tolerate a contradiction.
} 
between anti-Semitism and assimilation: showing that high identity anxiety (attempting to "pass" as a majority self) has a negative effect on information processing. ${ }^{26}$

The overall point of Garfinkel's initial research was that assimilation - a pillar of Parsons' argument - leads to a problematic situation in which marginalized identities are forced to try acting and thinking in ways that are as yet unfamiliar to them - and to do so while they are trying to make a social transition and/or trying to pass as persons of a majority category. As such, attempts to assimilate increase socialization failures and produce more contingency - rather than reinforcing normative socialization and reducing contingency as Parsons supposed. ${ }^{27}$

The big problem for sociology that Garfinkel set out to solve is that these processes tend to remain hidden and are consequently overlooked. The rules and expectations that actors orient, both in making social objects and identities, and in treating them, are "tacit" taken-for-granted features of what is typically called "commonsense." As such, these processes usually remain invisible to those who do not experience the systematic trouble that those presenting minority and disadvantaged identities experience. Research that does not make these hidden processes visible - and most research does not will by default incorporate inaccurate models of social processes and embed ethnocentric cultural biases: like assuming assimilation is a good thing. ${ }^{28}$

The awareness of unequal social processes such trouble can produce, called "double consciousness" by Du Bois, gave Garfinkel, as a Jewish minority, an awareness of "tacit" hidden structures in interaction. He drew on this awareness to demonstrate empirically why equality and reciprocity are necessary for successful interaction. This set him at odds with Parsons who, lacking minority insight, embraced the majority view. As a result, we argue, Garfinkel achieved a less ethnocentric and more scientific approach to sociology that prioritizes marginalized voices and centers social justice as a prerequisite.

The Development of the Trust Argument from 1948 The summer of 1952, after defending his dissertation, Garfinkel presented the first of many papers on the premedical candidate, titled "Anxiety and Social Perception of the Pre-Medical Candidate," at the Annual Meetings of the American Sociological Association (ASA). This we argue was the first of many "Trust" papers. Based on his dissertation (Chapters 18 and 24), it reported the results of an experiment with 28 pre-medical candidates. Notably, there is no mention of Jewish subjects or Jewish identity in the paper. The Harvard graduate school had required a change of title as a condition of approving his proposal. Garfinkel worked around that objection by focusing on the varying degrees of

\footnotetext{
${ }^{26}$ In other words, Americans who identify as White who have identity/status anxiety will be more likely to stick to preconceptions, while Americans (White or Other) without identity anxiety will be more likely to treat incongruous information as conflicting with their preconceptions.

${ }^{27}$ That the proliferation of cognitive dissonance as a coping mechanism leads to nonsense, was shown by the spread of conspiracy theories during and at the end of the Trump Presidency, which saw many Americans clinging ever more stubbornly and insistently to a set of beliefs that directly conflict with the society and "constitution" they profess to believe in. In other words, they assimilate incongruous information to preconceived beliefs, accommodating cognitive dissonance, while directing their anger toward socially marginal identities (see also endnotes 24 and 25).

${ }^{28}$ The point is the same in natural science: when you don't know how something actually works you can't model it. And when you can't model it you can't use big data. Once you get the model you can use it. But, to get the model you need to actually study the interaction between molecules, see Estrella et al., 2019, and Daily Kos in references.
} 
"anxiety" that all pre-medical candidates experienced during the experiment. The premedical candidate, on Garfinkel's rendering, experiences the same problems with Trust Conditions, and the standardization of everyday experience, that "The Jew" experiences. There are also striking parallels between Garfinkel's analyses of the pre-medical candidate and his subsequent research on Agnes, the "intersexed" woman who was the subject of his famous "Passing and the Managed Achievement of Sex Status in an 'Intersexed' Person" (Garfinkel, 1967: Chapter 5).

The troubles revealed by Garfinkel's early studies of minority experience were used from 1948 on as the basis of a more general approach to taken-for-granted social processes, the reciprocities of practice they depend on, and how troubles reveal them.

"Tribal" Thinking and Marginal Identity "Tribal" thinking is the name Garfinkel gave to the practice of prioritizing the judgment of the majority group over one's own, and doing so even when it results in holding contradictory ideas. Because the pre-medical candidate has not yet achieved the identity "medical candidate", they cannot take for granted that they are making sense of the situation the same way relevant others are, particularly those who control entry into medical school. The student relies on the assessment of what Garfinkel calls "status superiors" to distinguish "what is objectively the case" from what is "mere appearance" (Garfinkel, 1952b:6). This "tribal" thinking involves a marginal identity trusting the group they are trying to join to assess their identity performance, while distrusting their own evaluation - even when doing so results in contradiction. As Garfinkel says, the person in this position "distrusts his sense of an event if its sense appears to be peculiar or private to him, fearing that such an interpretation is unrealistic" (Garfinkel, 1952b:6). Holding contradictory ideas/beliefs - cognitive dissonance - is the frequent result.

The pre-medical candidate, Garfinkel argues, structures their life and their way of treating incongruity around the objective of getting into medical school. In pursuing this goal, the student works at "bringing ever more areas of his life under conceptual control" (Garfinkel, 1952b:2). Given what they have already accomplished, the student feels "entitled" to be admitted - there is a "moral requiredness" about it (Garfinkel, 1952b:3). Despite this sense of entitlement, however, they know admission is not a foregone conclusion, and are acutely aware that even the smallest contingencies can derail the plan. ${ }^{29}$

This makes the pre-medical candidate interesting to the sociologist as a source of insight into how social interaction works. As Garfinkel (1952b:3) says, Trust Conditions are harder to meet and "the pre-medical candidate becomes a philosopher through necessity". He proposes that this heightened awareness - "double consciousness" in Du Bois' terms - and the authority it can confer on others to determine objective reality can lead to accepting contradictory information. It is a characteristic of those who find themselves in precarious identities (unless, like most Black Americans, they develop their

\footnotetext{
${ }^{29}$ In 1960, while attending Parsons' seminar at Harvard, Garfinkel and Sacks talked about how being a doctor is the only identity a Jewish person can get that counts (audio in archive). Without it you are nothing according to Sacks.
} 
own Interaction Order with expectations that support their marginal status, Rawls 2000, Rawls \& Duck, 2020). ${ }^{30}$

In the all-important interview with the admissions officer the problem is that, regardless of how much they prepare, "the interviewer will make his own kind of sense of what the candidate says and does" (Garfinkel, 1952b:9). Since the interviewer's interpretive criteria are not available to the candidate, they cannot be sure if they are making sense to the interviewer. Garfinkel (1952b:9) likens the situation to one where a person is:

[F] aced with the task of shooting at a target which he must designate himself, not knowing whether or not he will be shooting at the correct one, but knowing the consequences to himself should it turn out that he has selected incorrectly, and knowing as well that he will be held responsible for selecting a proper target as well as for the score he makes.

All marginal identities, and persons trying to assimilate, find themselves in this situation vis a vis the majority. The pre-medical candidate and "The Jew" inhabit similarly problematic identities.

They face, as Garfinkel would put it in a later version of the Trust paper, a similar "built in structural dilemma" by virtue of their social position as "outsiders" (Garfinkel, 1956). Both aim at targets they have to designate for themselves, needing to guess at the standards they will be held to, while nonetheless being held responsible for meeting those standards.

The pre-medical candidate must "wait for the other to tell him at any moment who he is in the interviewer's eyes" (Garfinkel, 1952b:10). Not knowing "who they are" for the Other, the self the Other reflects back to the candidate could well be unrecognizable to them: a "fractured reflection" (Rawls \& Duck, 2017) of what was intended, but which the candidate must, nevertheless, somehow accept. This is a risk faced by all selves, whose existence as social objects depends on ratification by others with whom they often have little in common (Goffman, 1959). But, for majority persons the process is rarely problematic, while for those in marginalized (or transitioning) identities the troubles are omnipresent: they can never be sure they are getting it right. This disadvantage is structured into the very systems of interaction - Interaction Orders - in which everyone is required to participate.

The Case of "Agnes" and Fourteen Other Transsexuals ${ }^{31}$ When Garfinkel met Agnes in 1958, she was one of several dozen people (called "intersex" at the time) who were being treated by Psychiatrist Robert Stoller at the UCLA gender clinic (see also Schilt forthcoming). Agnes sought gender reassignment surgery and needed to navigate Stoller's requirements to succeed. Although he would ultimately publish only what he wrote about Agnes (Garfinkel, 1967), Garfinkel also met with and interviewed 14 other intersex persons, most of whom he met through the clinic.

\footnotetext{
${ }^{30}$ In their book Tacit Racism, Waverly Duck and Anne Rawls argue that the identification of lower and middle status White Americans with rich White Americans leads to a similar state of vulnerability in which they can be manipulated by tribal thinking. This would explain at least part of the Trump phenomenon.

${ }^{31}$ When Garfinkel initially did the research, the terminology was different from what it is today. This discussion will use a mix of current and historical terminology to reflect the ongoing discussion - just as we did for Race terms.
} 
Agnes' narrative was that she was born a biological male, but began developing feminine traits at puberty. She was seeking sex-reassignment surgery from Stoller, who would only perform the surgery on "naturally" intersexed candidates. Biological men who wanted to become women (i.e. transsexuals), and vice versa, were not eligible for the surgery at the time. To qualify for the surgery Agnes had to convince Stoller that her biology was ambiguous. Several years after the surgery, she reported that she had started taking female hormones in early adolescence (i.e. she was transsexual, rather than biologically intersexed), which by Stoller's criteria would have made her ineligible for the surgery. But, while she was being evaluated for the procedure, she tailored her narrative to Stoller's requirements and was able to "pass" convincingly.

It was this "passing" that made her interesting to Garfinkel. ${ }^{32}$ It meant that she had mastered the expectations for being female in a conscious way that she could talk about. Garfinkel described Agnes and the pre-medical candidate in similar ways. The pre-med was "a philosopher through necessity" (Garfinkel, 1952b:3). Agnes was a "practical methodologist" (Garfinkel, 1967:183).

Both had developed heightened states of awareness - a double consciousness - that provided a window for the sociologist into how social interaction was organized.

In her conversations with Garfinkel, Agnes explained that because she had not been raised as a girl, being female did not come naturally to her. She needed to consciously learn how to act to be seen as female - often at the same time that she was doing it. Garfinkel (1967:146) describes what he called her "secret apprentice" strategy. Agnes secretly observed and modeled the behavior of other women. This and other strategies enabled her to learn enough about how women are expected to act so that she could usually "pass" as an ordinary female. Despite her success, however, Agnes remained on guard for contingencies that could expose her secret and lead to social ruin.

Like "The Jew" who was trying to assimilate, Agnes experienced identity anxiety, and was consequently engaged in a kind of tribal thinking that required her to accept the judgment of Others on her performance. She could never achieve the kind of taken-forgranted routine that sexual "normals" achieve. Because she was born male, in presenting a female identity she could also not comply with the constitutive expectancy of the time that everyone is either male or female, and that people are what they appear to be.

We read that for Agnes, the remedy for her condition "had a moral requiredness" (Garfinkel, 1967:177) just like it did for the pre-medical candidate. Moreover, just as the pre- medical candidate interpreted everything in terms of its bearing on the chances of getting into medical school, Agnes interpreted the events in her life in terms of their bearing on getting her surgery: "Very few things could occur for Agnes, bearing in their relevance on "her problem," in an accidental or coincidental manner" (Garfinkel, 1967:177).

Of particular importance to Garfinkel's interest in how marginal identities treat incongruity is the finding that, like the pre-medical candidate, Agnes distrusts her own private impressions. Thus, her "rules of evidence are of...tribal character. They could be summarized in a phrase: I am right or wrong on the grounds of who agrees with me" (Garfinkel, 1967:179). Like others who aspire to achieve membership in a group that is not their own, she could not trust her own opinions. Both Agnes and the pre-med are forced to fall back on a consensus-based way of treating incongruity in

\footnotetext{
$\overline{32}$ Garfinkel and Goffman had planned to publish a book together in 1962 titled On Passing and Stigmatized Identity. The book would have combined Garfinkel's study of Agnes with Goffman's essay on Stigma.
} 
which right and wrong are determined once and for all by criteria external to themselves and to any given interaction. ${ }^{33}$ Indeed, in Agnes' case, commitment to the majority belief in a male/female binary leads her to reject other persons like herself. Without secure membership, group consensus becomes the fallback for determining the appropriateness of an identity, or course of action, with negative implications for social justice.

Collaboration with Parsons, 1958-1966 As Garfinkel developed his argument about Trust and the experiences of those in marginal identities through the 1950s, Parsons was moving away from his earlier emphasis on the "actor's point of view" and increasingly focusing on what actors must do together to assemble social order and meaning. Although he did not share Garfinkel's concern for marginal identities per se, he did share Garfinkel's recognition of the importance of separating culture from structure and locating culture as the sui generis site where social facts are produced in interaction. That Parsons was aware of the affinities between their positions is evidenced by his invitation to Garfinkel to attend the Harvard conference in 1958 and his subsequent participation in a conference in Los Angeles in 1964 with Garfinkel, Sacks and Goffman.

In a letter dated July 14, 1958, the day before Parsons left the Center for Advanced Studies at Stanford where he had been working on a new manuscript, he invited Garfinkel to attend a conference of Parsons' close associates at Harvard that September. The conference would introduce five of his former students and colleagues (Garfinkel, Kaspar Naegle, Jim Olds, Robert Bales, Robert Bellah, and Neil Smelser who was not able to attend) to his recent work.

Letters between Garfinkel and other attendees make it clear that Parsons had invited those of his students with serious theoretical interests to return from far-flung places to advise him. ${ }^{34}$ Naegle was in British Columbia, Garfinkel in Los Angeles and Smelser at Berkeley (Olds, Bales and Bellah were already at Harvard). Parsons included Garfinkel in this group of close and valued associates and wanted him by his side.

The seriousness with which Garfinkel took this invitation is evident in a letter he wrote Parsons on August 19, 1958, less than a month before the meeting, in which he described his preparations for the conference:

"I've put everything aside in order to work through your manuscripts. The reading is going slowly because I am trying to manage several tasks in the reading: to grasp the intended sense of your formulations; to sort the corpus into its analytic parts and to reread and interpret these parts in light of my own concerns. Also, I've taken the

\footnotetext{
33 The Biden election, which entered the electoral college phase as we were writing this article, is a good illustration of Garfinkel's point. After many decades of taking the democratic process for granted, the threat to the system inspired by Trump, created a level of "trouble" that is revealing the hidden processes of US democracy. On December 14, 2020 millions of Americans watched Electoral College Electors cast their votes in all 50 states, something that has not been a nationwide spectacle before. As with Agnes and the pre-med, those with identity anxiety who cling to their Whiteness as if it entitled them to special privileges have stuck to their preconceptions through thick and thin - making them easy to manipulate. Those who are clear about who they are, however, and what they stand for - anti-racism and equality - have been able to see clearly through the disinformation. That wanting to join the majority and pass as White makes one into a "cultural dope" is a key insight.

${ }^{34}$ It is clear from this letter that there had been a prior inquiry about this invitation. But that letter has not yet been found, so we don't know how far in advance Parsons began planning for the conference.
} 
conference as an occasion to re-read Durkheim. The whole effort has turned into an "experience"."

We know Garfinkel and Parsons discussed the course he proposed to teach on Parsons' work, and his plan to prepare a manuscript on the basis of it, because on January 22, 1959, he wrote asking Parsons to send copies of four pieces of his work for students to read in that seminar, mentioning both the seminar and the Primer manuscript as if they had already been discussed, and promising to tell Parsons more about his plans soon. ${ }^{35}$ The UCLA seminar in 1959 was titled Contemporary Sociological Theorizing, and designated SO 172 (in 1963 it was renumbered SO 251). The syllabus shows that, while focusing on Parsons, the seminar also covered related materials, including articles by Parsons' students.

Garfinkel wrote Parsons again on January 29, 1959, telling him that his plan was to teach Parsons' materials backwards as a way of keeping the discussion current, and avoiding the focus on the development of Parsons' ideas that he thought would come from dealing with them chronologically. Garfinkel ([1962]2019: appendix) wanted to emphasize the relevance of Parsons' mature approach to the "current situation of the discipline":

"I've decided to teach your materials by using the most recent writings as the precedent for reading the earlier ones. Reading the corpus "backwards" lends to the earlier work, its sense of what you have been up to "all along" or "after all". The criticisms of such a rereading procedure, i.e., that it produces an "interpretation" of Parsons, or that it reads Parsons for something more, less, different, better, worse than he intended, are easily met. A chronological reading would be difficult to carry off without making the development of your ideas a central theme. I feel that the seminar, and a "Primer" based upon it, should be directed to the uses to be made of your materials in the current situation of the discipline."

Explaining how Parsons' position was relevant to the distressing situation post-war sociology found itself in, Garfinkel wrote that the "current situation" as exemplified by his own department, was an "impoverished knowledge...of sociological theory", combined with an imbalance in favor of statistical methods and against social interaction, that left students and faculty alike in a paradoxical state of "fear" and "interest" regarding social theory. Garfinkel proposed to solve the problem by explaining why Parsons' emphasis on social interaction and the independence of the interactional dimension of culture is a necessary foundation for sociology.

The way Parsons positioned social interaction/culture at the center of his social system, grounding it on social contract and insisting on its independence from social structure, was an essential foundation for Garfinkel's own studies of ethno-methods and his Trust argument. At the time, Garfinkel was still hoping that a revised Parsonian theory that approached interaction in terms of (what Durkheim ([1893]1933), called) self-organizing practices, on the basis of studies of actual interaction, could improve the situation of sociology.

By the time Garfinkel completed Parsons' Primer in 1962, Parsons' position had moved closer to Garfinkel's than at any time before. Parsons had developed and refined

\footnotetext{
${ }^{35}$ In these letters there are many requests for materials, as well as requests to return materials given previously. This exchange of materials is in itself important. Because this work was being done in the era before Xerox, sharing unpublished work required maintaining trusted relationships.
} 
the Pattern Variables to explain how members of society achieve a shared orientation to social objects and situations, and had begun to equate norms and values with Garfinkel's assembly rules and practices. For his part, Garfinkel was using his studies in ethnomethodology to empirically ground Parsons' theory. For all their similarities, however, irreconcilable differences remained.

Differences: Parsons Vs. Garfinkel on Value Uniformity and Stratification Of all the differences between Garfinkel and Parsons, the most consequential was their disagreement over contingency, which led to differences in their approaches to stratification, value unification, deviance, and social justice. For Parsons, contingency remained a problem, even as his position became more interactional. Too much contingency, on his view, threatened the stability of social order and meaning, which made standardization and assimilation necessary. Parsons tried to solve this problem analytically by limiting the options for social interaction through the Pattern Variables.

Nowhere are the consequences of Parsons and Garfinkel's disagreement over contingency more apparent than in their respective approaches to stratification. Because he posited the need for a single overarching value system in a society, and voluntary assimilation to that value system, Parsons' model needed to reward conformity and punish deviance. Even though he recognized that there could be many value systems in any given society - which he conceptualized as systems, subsystems, sub-subsystems, etc. - he insisted that there must be a single higher-order value system to which all members of a society subscribe. Even as he moved further toward social interaction, Parsons sent Garfinkel a paper in 1963 for students to read in Garfinkel's seminar on Parsons. In the paper, Parsons (Garfinkel, 1963; Parsons, 1989) called what he identified as the dominant U.S. value system "instrumental activism," arguing that it had deep cultural roots in the worldly asceticism of Protestant reformers. ${ }^{36}$

These values, Parsons argued, are learned through socialization and reinforced through sanctioning deviant behavior. This way of dealing with contingency required the elevation of one value system above the rest, which also elevated its members to higher levels of a stratification system. This was all to be enforced by the pressure to assimilate, and punishment for deviance that Garfinkel had been documenting as a source of both inequality and cognitive dissonance.

As a Jewish man who had spent his life dealing with exclusion and discrimination, Garfinkel was acutely aware that the dominant social order was problematic. He did not share Parsons' faith in either assimilation or the Protestant Ethic. Garfinkel's research on marginal populations - Black, Jewish, Criminal, Mentally-ill, Transsexual, Blind, Red - also showed him that members of such groups develop an awareness of the achieved character of social order that those in dominant groups lack. Therefore, it was the marginal and not the majority that Garfinkel felt held the key to understanding society. The minority awareness that society is a situated achievement at every point opens the possibility of treating practices and expectations as local achievements - that can be altered as needed - without reference to an overall standard.

\footnotetext{
${ }^{36}$ The manuscript of this paper in the Garfinkel Archive was sent to Garfinkel by Parsons in 1963 in response to a request from Garfinkel for some of Parsons' recent work. It was one of the four pieces Parsons sent in response to that request. The manuscript remained unpublished until 1989.
} 
Durkheim ([1893]1933) referred to this as "self-regulation" and argued that it becomes necessary when diversity, science, and occupations became too complex to be regulated by general standards.

Furthermore, for Garfinkel contingency was a solution, not a problem. The problem was standardization, and the stratification, assimilation and inequality that follow from it. Garfinkel treated variability of positioning within a practice, and the situated character of practices themselves, as resources for making meaning in diverse populations that do not share a broader cultural system of meaning. Such assembly practices are localized which allows for both variability and flexibility. Where people recognize each other as equals who are committed to an implicit social contract - Trust Conditions - they can use constitutive practices in many creative ways to make meaning and order from contingency, and do so over and over again, on the spot.

Treating cultural assembly work as localized around situated knowledge practices, as Durkheim and Garfinkel did, instead of conceptualizing culture as a uniform set of practices - or Pattern Variables in a unified context of values - aligns with the pursuit of social justice.

Maximizing contingency in terms of variations in sequential positioning is also a useful and efficient way to create new meanings against sets of expectations in social interaction, just as it is in games. If there is no need for uniformity, there is no need to suppress deviance, stratification does not add resilience to social order, and local practices can all be treated as equals (insofar as they do not violate equality conditions).

Differences: The Different Meanings of "Trust" in Garfinkel and Parsons Disagreement between Garfinkel and Parsons is also apparent in their clashing conceptions of Trust/ trust and its role in achieving social order and meaning, for evidence of which we turn to correspondence from Parsons to Garfinkel in 1963. For Garfinkel, Trust Conditions - which set requirements for reciprocity in the use of constitutive practices - are a prerequisite for social order. Participants in interaction must be able to display their commitment to Trust Conditions, turn-by-turn, in their responses to immediately prior turns, in order to make sense together. This need makes equality necessary. When Trust Conditions are violated situations become unintelligible and participants cannot make sense together.

For Parsons, by contrast, trust is not a prerequisite for interaction. In his view participants can gain or lose trust over a sequence of turns without the intelligibility of the interaction being at stake. Parsons lets standardization do the job of controlling contingency, while assuming that participants share the uniform value system necessary to make meaning together. Having been socialized into the same social values, they can take a commitment to those values for granted. On this modified "consensus" view, there is no need to meet situated conditions for constitutive practice and consequently no need for equality and reciprocity in principle.

This difference comes up in one of Parsons' letters to Garfinkel dated January 30, 1963. In that letter, Parsons refers to the "awakening of trust" over the course of interaction. Commenting on what he describes as Garfinkel's argument that participants must be committed to "what we refer to as norms - as a sufficiently stable object so that orientation in terms of this perception is meaningful," Parsons notes that "disturbance at this level does not imply alienation in the usual sense of incapacity to accept normative 
obligations. It lies rather at the level of definition of the situation" (Garfinkel, [1961]2019: 355). Parsons then writes:

"What in my paper on influence I have called the 'dimension of justification' seems to me to be the connecting link looked at from the point of view of awakening of trust, rather than having it. That is a justification as part of the complex persuasion is a reference to a meaningful context of behaving in the way the persuader wants the behavior to occur. Mutual trust between is the premise on which this type of persuasion can be expected to operate."

Parsons treats trust here as an aspect of persuasion, something a person who is attempting to exercise influence over a co-participant can gain or lose. Garfinkel, on the other hand, treats Trust as a constitutive condition on which the very possibility of identities like "persuader" and "persuaded" depend. For Garfinkel Trust includes the constitutive rules of the situation and mutual commitment to them. This difference between Garfinkel and Parsons is intimately bound up with their respective approaches to contingency and effects their positions on equality, reciprocity, and the need for social justice.

The Importance of Parsons to Garfinkel's Approach Garfinkel always said that ethnomethodology began with Parsons. By centering social contract and interaction, Parsons' revival of Durkheim provided Garfinkel with a framework for situating the problem of social order. It was the potential he saw in Parsons' theory that inspired Garfinkel to go to Harvard to work with him in the 1940s, and which led to their later collaboration.

In a talk titled "The Program of Ethnomethodology," delivered at Berkeley in 1961, Garfinkel ([1962]2019: 336) explains why this framework was important to him: "We have consulted Parsons' theory of social systems to aid in collecting our thoughts about the stable structures of normatively regulated interpersonal transactions. Most particularly, however, I have borrowed from Parsons' work in which he delineated the constituent tasks that make up the problem of social order." While Garfinkel drew on Schutz's “constitutive phenomenology of everyday life" (Garfinkel [1962]2019: 336) to describe the practices by which social meanings are achieved, he drew on Parsons to develop his argument about how those practices are embedded in independent cultural systems of interaction, all grounded in an implicit social contract.

While there is far more synergy between Garfinkel and Parsons than the history of sociology typically recognizes, the two disagreed on how people were making meaning and order evident in social interaction. Parsons focused on conformity to a limited set of pattern variables, while Garfinkel not only suggested a much larger and varied set of expectations - but argued that they could always be adapted in situ - his famous "etcetera" clause.

As a consequence of their different approaches to how social facts are assembled, and to the role of contingency and Trust/trust in the process, Parsons and Garfinkel end up with different political stances. Because he limited the number of variables involved in sensemaking, Parsons held that some degree of general social stratification, conformity and assimilation is not only inevitable, but desirable, and that deviance must be suppressed. Garfinkel, on the other hand, was only interested in what Parsons considered deviance insofar as it created "trouble" that could reveal how some categories of people have difficulty achieving "normal" meanings and identities. He did not treat their troubles as deviance, but rather as troubles frequently encountered by those in 
marginalized statuses and categories as they try to make sense in society. The problem for such identities is that they have already been defined by society as deviant.

While valuing Parsons' conceptions of culture and social contract, Garfinkel criticized Parsons' theory of stratification. As he wrote in Parsons' Primer (Garfinkel, [1962]2019: 306), "remember this is Parsons' version of a society. The frequency with which we encounter persons who see through a great deal of the moral order is not convincingly handled with the use of Parsons' society. Such persons are not the cultural dopes that sociological theory frequently portrays them to be." ${ }^{37}$ As a minority who had frequently experienced exclusion because he was Jewish, we speculate that Garfinkel had himself in mind when he wrote these lines. He could "see through" Parsons' "moral order", as could Du Bois, Agnes, and other marginalized identities. Garfinkel's view was that there are many ways of making sense together. What is necessary is to get all local participants oriented toward the same situated Trust Conditions and then they can use variation and innovation to make meaning.

\section{Conclusion}

Ethnomethodology, Politics, and Social Justice in the $21^{\text {st }}$ Century Garfinkel followed Durkheim in maintaining that social order in diverse and differentiated societies is achieved not in spite of diversity but because of it. This requires a big change in how social order is conceived. This modern diverse social order requires a new kind of moral order that does not embed cultural bias and punish difference. Durkheim called it justice. It requires flexibility in the form of constitutive practices whose details can be endlessly rearranged to make meaning together. It also requires detailed research that can reveal the structures of sense-making and the hidden structural biases that lurk in interactional practices.

Garfinkel documented the importance of local constitutive practices in freeing meaning from symbolic belief systems. As Durkheim ([1893]1933) argued, this development explains the possibility of modern sciences and occupations, as well as the possibility of communication across diversity. But, it requires not only flexibility in the use of contingency, but also equality and reciprocity. Parsons parted company with Durkheim on this point. Garfinkel's position is consistent with Durkheim's argument that self-regulating "constitutive" practices that require justice need to replace traditional "rules by summary" in diverse modern societies, particularly in occupations and sciences (Durkheim [1893]1933; Rawls, 2021; Rawls \& Turowetz, 2019).

Critics like to say that equality cannot be a prerequisite for using constitutive practices because there is a great deal of inequality and yet "things work just fine". But, those who say this have not been paying attention. As Garfinkel demonstrates, things are not working fine at all for those in minority positions. Things only appear to be working fine if we either 1) do not interact across groups (excluding minorities from majority interactions), which is all too common, or 2) deny the validity of the minority viewpoint when interaction across groups does occur, the prevalence of which is one reason minority insights have been so systematically excluded.

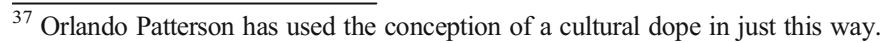


In other words, the claim that things are working just fine in spite of inequality is itself exclusionary: only supportable from a majority perspective that denies the legitimacy of minority experience. Therein lies the problem with the sort of conformity Parsons thought was necessary and desirable. Of course, Parsons was hardly unusual or alone in his belief, which was common among liberal intellectuals, who have typically seen deviance as a "social problem" to be solved, whether through institutional reforms, or remedial efforts targeting "cultures of poverty" (e.g. Lewis, 1959; Moynihan, 1965). Garfinkel's point is that to assimilate, or "fit in," the socially marginal are forced to accept contradictions and suppress their own experience of exclusion - as exemplified by Agnes who avoided others like herself because, as she put it, "I didn't want to be classified with them" (Garfinkel, 1967: 131) - and then forced to live with the identity anxiety and cognitive dissonance that results. Refusing to assimilate is one solution.

Garfinkel's discovery that the way participants use constitutive practices to make the "normal" and "natural" social life we take for granted can be specified empirically allowed him to document the trouble that inequality produces in detail: a point that had remained abstract and theoretical for both Parsons and Durkheim. His articulation of Durkheim's "justice requirement" as Trust Conditions that must be demonstrably met in witnessable empirical details, was broader than Durkheim's original (Rawls \& Turowetz, 2019); requiring equality and reciprocity not only of position (lack of forced labor), but also of access to the witnessable reciprocities involved in using constitutive practices (as in Marcel Mauss' (1924) The Gift). Garfinkel's constitutive practices were also more situated and flexible than Parsons' Pattern Variables.

The detail required to document these interactional processes has seemed unnecessary to those conventional sociologists who take social fact making for granted and imagine that social practices can be abstractly specified in generic terms. Assumptions about the superiority of generic and abstract approaches, combined with a strong turn against studies of interaction and toward statistics during and after WWII, and a bias toward majority thinking, have prevented sociologists from appreciating the need to examine social fact making processes in detail.

Just as sociology is weaker theoretically because of its lack of attention to interaction and qualitative methods, a lack of attention to inequality and other social justice issues imbedded in social interaction has weakened the discipline politically. The voices of excluded sociologists (including Du Bois ([1903]2015) and Eric Williams (1943)) who long ago called attention to the cultural biases embedded in what we like to think are scientific methods, have been marginalized. Racism and anti-Semitism (Rawls, 2018) have been allowed to push Garfinkel and other minority thinkers to the margins, obscuring the importance of their positions, their relevance to social justice, and in Garfinkel's case, the connection to efforts by his close Jewish colleagues, Egon Bittner, Erving Goffman and Harvey Sacks, to articulate a theory of society that would put social interaction and its moral requirements at the center (Duck \& Rawls, 2020; Rawls et al., 2020).

Funding Open Access funding enabled and organized by Projekt DEAL.

\section{Declarations}

Conflict of Interest The authors have no conflicts of interest to declare that are relevant to the contents of this article. 
Open Access This article is licensed under a Creative Commons Attribution 4.0 International License, which permits use, sharing, adaptation, distribution and reproduction in any medium or format, as long as you give appropriate credit to the original author(s) and the source, provide a link to the Creative Commons licence, and indicate if changes were made. The images or other third party material in this article are included in the article's Creative Commons licence, unless indicated otherwise in a credit line to the material. If material is not included in the article's Creative Commons licence and your intended use is not permitted by statutory regulation or exceeds the permitted use, you will need to obtain permission directly from the copyright holder. To view a copy of this licence, visit http://creativecommons.org/licenses/by/4.0/.

\section{References}

Coleman, J. (1968). Review symposium. American Sociological Review, 33, 126-130.

Coser, L. (1975). Two methods in search of a substance. American Sociological Review, 40(6), 691-700.

Du Bois, W, E, B. ([1903]2015) The souls of black folk. Yale University Press

Dubin, R. (1960). Parsons' actor: Continuities in social theory. American Sociological Review, 25(4), 457466.

Duck, W., \& Rawls, A. W. (2020). Developing a White “double-consciousness" of race and marginality: Implications of Du Bois and Garfinkel for scientific awareness of interaction orders. Unpublished Manuscript.

Dubin, R. (1960). Parsons' actor: Continuities in social theory. American Sociological Review, 25(4), 457-466.

Durkheim, E. ([1893]1933). Division of Labor in Society, trans. George Simpson. Free Press.

Eglin, P. (2017) This and that: Garfinkel, Wittgenstein and the world in 2017. Plenary address, IIEMCA, Otterbein University, Westerville, OH, 10 July.

Fanon, F. (1952). Black skin, white masks. Editions du Seuil.

Festinger, L. (1957). A theory of cognitive dissonance. Stanford University Press.

Garfinkel, H. (1940). Color trouble. Opportunity, 18(5), 144-152.

Garfinkel H (1942) Inter-Racial and Intra-Racial Homicide in Ten Counties in North Carolina, 1930-1940. Unpublished MA Thesis, University of North Carolina, Chapel Hill (Abridged version published in Social Forces 1949 (27)370-381).

Garfinkel, H. (1946) Some reflections on action theory and the theory of social systems. Unpublished manuscript, Garfinkel Archive.

Garfinkel, H. (1948). A further note on the prospectus for an exploratory study of communication and the modes of understanding in selected types of dyadic relationship, with particular reference to the Jew as an object of social treatment. Unpublished manuscript, Garfinkel Archive.

Garfinkel, H. (1949). Research note on inter- and intra-racial homicide. Social Forces, 27, 370-381.

Garfinkel, H. (1952a) The perception of the other. Unpublished dissertation, Harvard University.

Garfinkel, H. (1952b) Anxiety in the premedical candidate. Unpublished manuscript, Garfinkel Archive.

Garfinkel, H. (1956). Some structural dilemmas of pre-medical candidates. Unpublished manuscript, Garfinkel Archive.

Garfinkel, H. (1962). Parsons' primer. Springer.

Garfinkel, H. (1963). A conception of and experiments with 'trust' as a condition for stable concerted actions. In O. J. Harvey (Ed.), Motivation and social interaction (pp. 187-238). Ronald Press.

Garfinkel, H. (1967). Studies in ethnomethodology. Prentice Hall.

Garfinkel, H. ([1947]2012). “The Red as an Ideal Object.” Etnografia e Ricerca Qualitativa, 5(1), $19-34$.

Garfinkel, H., \& Weider, D. L. (1992). Two incommensurable, asymmetrically alternate Technologies of Social Analysis. In G. Watson \& R. M. Seiler (Eds.), Text in context (pp. 175-206). Sage.

Goffman, E. (1959). Presentation of self in everyday life. Anchor.

Kroeber, A. L., \& Parsons, T. (1958). The concepts of culture and of social system. American Sociological Review., 23, 582-583.

Lewis, O. (1959) Five families. Basic Books.

Meehan, A. J. (1986). Record-keeping practices in the policing of juveniles. Urban Life, 15(1), 70-102.

Meehan, A. J., \& Ponder, M. C. (2002). Race and place: The ecology of racial profiling African American motorists. Justice Quarterly, 19(3), 399-430.

Moynihan, D.P. (1965) The Negro family: The case for national action. No. 3. US Government Printing Office. 
Park, R. (1926) The concept of position in sociology. American Sociological Review.

Parsons, T. (1937). The structure of social action. The Free Press.

Parsons, T. (1938). The role of theory in social research. American Sociological Review, 3, 13-20.

Parsons, T. (1951). The social system. Free Press.

Parsons, T. (1960). Pattern variables revisited: A response to Robert Dubin. American Sociological Review, 25(4), 467-483.

Parsons, T. (1989). A tentative outline of American values. Theory, Culture, and Society, 6(4), 577-612.

Rawls, A, W. (2021) "Durkheim's Self-Regulating "Constitutive" Practices: An Unexplored Critical Relevance to Racial Justice, Consensus Thinking, and the Covid-19 Pandemic." In Durkheim \& Critique. Ed. Nicola Marcucci. Palgrave Macmillan.

Rawls, A. W. (2018). The wartime narrative in US sociology, 1940-1947: Stigmatizing qualitative sociology in the name of 'science'. European Journal of Social Theory, 21(4), 526-546.

Rawls, A.W. (2000). "Race" as an Interaction Order Phenomenon: WEB Du Bois's "Double Consciousness" Thesis Revisited. Sociological Theory 18(2):241-274.

Rawls, A. W., \& Duck, W. (2020). Tacit racism. University of Chicago Press.

Rawls, A, W. \& Turowetz, J. (2019) "Discovering culture" in interaction: Solving problems in cultural sociology by recovering the interactional side of Parsons' conception of culture". The American Journal of Cultural Sociology.

Rawls, A. W., \& Duck, W. (2017). "Fractured reflections" of high-status black male presentations of self: Nonrecognition of identity as a "tacit" form of institutional racism. Sociological Focus, 50(1), 36-51.

Rawls, A. W., Whitehead, K., \& Duck, W. (2020). Black lives matter: Ethnomethodological and conversation analytic studies of race and systemic racism in everyday interaction. Routledge.

Sartre, J. P. (1995 [1945]). Anti-Semite and Jew. Schocken Books.

Schilt K (forthcoming) Sex and the sociological dope: Garfinkel's intervention into the emerging disciplines of sex/gender. In: Maynard DW and Heritage J (eds) Harold Garfinkel: Praxis, Social Order, and the Ethnomethodology Movement. Oxford University Press.

Smith, M. B., Bruner, J. S., \& White, R. W. (1956). Opinions and personality. John Wiley and Sons.

Sudnow, D. (1965). Normal crimes: Sociological features of the penal code in a public defender office. Social Problems, 12(3), 255-276.

Turowetz, J. \& Rawls, A, W. (2020) The Development of Garfinkel's “Trust” Argument from 1947 to 1967 : Demonstrating How Inequality Disrupts Sense and Self-Making. Journal of Classical Sociology. Published online January 5 2020. https://doi.org/10.1177/1468795X19894423.

Weider, D. L. (1974). Language and social reality. University Press of America.

Williams, E. (1943). Capitalism and slavery. University of North Carolina Press.

Znaniecki, F. (1936). Social actions. Farrar and Reinhart.

Publisher's Note Springer Nature remains neutral with regard to jurisdictional claims in published maps and institutional affiliations. 